\title{
Presentation Pattern and the Value Relevance of Comprehensive Income --- Evidence from China
}

\author{
Wenjing $\mathrm{Xu}^{1}$ \& Ming $\mathrm{Qi}^{1}$ \\ ${ }^{1}$ China University of Petroleum, Beijing, China \\ Correspondence: Wenjing Xu, School of Business Administration, China University of Petroleum, Beijing, NO. \\ 18 Fuxue Road, Changping District, Beijing, China. E-mail: xuwenjing @ cup.edu.cn
}

Received: March 20, 2017

Accepted: April 13, 2017

Online Published: May 5, 2017

doi:10.5539/ijef.v9n6p31

URL: https://doi.org/10.5539/ijef.v9n6p31

\begin{abstract}
In 2006 the Chinese Ministry of finance(CMF) issued new accounting standards that required companies began to present comprehensive income information in the statement of equity. In 2009 and 2014, CMF changed the comprehensive income presentation pattern consecutively twice, from the equity statement pattern to the performance statement transition pattern, and then to the single performance statement. The purpose of these changes is to harmonize China Accounting Standard (CAS) with International Financial Reporting Standards(IFRS). It also aims to enhance the usefulness of comprehensive income information by improving the transparency of information disclosure. From the perspective of presentation patterns, the paper examines the influence of presentation pattern changes on the value relevance of comprehensive income (CI), and on other comprehensive income (OCI). The results show that, under the equity statement pattern, neither CI nor OCI was correlated with value. Under the performance statement transition pattern, both CI and OCI have the value relevance. Under the single performance statement pattern, the CI has higher value relevance, while the OCI does not reflect higher value relevance. This study reveals the impact of comprehensive income presentation pattern on the usefulness of decision making. It has certain inspiration and reference for improving the quality of accounting standards and financial reporting.
\end{abstract}

Keywords: presentation pattern, value relevance, comprehensive income, other comprehensive income

\section{Introduction}

In order to improve the usefulness of accounting information, it has become the common sense for the accounting standards setting organizations to report "comprehensive income information", which include both comprehensive income $(\mathrm{CI})$ and other comprehensive income $(\mathrm{OCI})$. However, the debate over the presentation pattern of comprehensive income information has been going on for decades. From the practice of various countries, the main focus is whether the comprehensive income information should be listed in the statement of equity, or listed in the performance statement. If listed in the performance statement, another debate arises. It should be listed in two performance statements or in a single performance statement. In June 2011, the International Accounting Standards Board (IASB) officially released the research output --- "presentation of Items of other comprehensive income" (revision of IAS1). It determines the "one or the other" pattern for comprehensive income presentation, which allows entities to choose a single performance statement or two performance statements to present the comprehensive income information.

In the context of full convergence with International Financial Reporting Standards(IFRS), China accounting standards began to introduce the idea of comprehensive income in 2006. It required companies to present comprehensive income information in the equity statement. In 2009, the Chinese Ministry of finance (CMF) issued "enterprise accounting standards interpretation No. 3", which required companies to present total comprehensive income (CI) and total other comprehensive income (OCI) in the performance statement. In 2014, CMF issued "enterprise accounting standards No. 30-presentation of financial statements" (revised edition), which further required companies to present the components of OCI in performance statement in categories, instead of disclosure in the notes. The purpose of these presentation pattern changes in China is to improve the usefulness of accounting information by enhancing the transparency of information disclosure and reducing the cost of information acquisition. So, do the presentation pattern reforms above have reached this purpose? This paper examines this problem by investigating the real effects of presentation pattern changes. It provides some 
theoretical and practical implications for the further improvement of the relevant standards.

\section{Background, Prior Research and Hypotheses Development}

\subsection{Background}

The traditional accounting income is based on the historical cost, the realization and the conservatism principle. Unrealized value changes are not recognized. Since 1990s, fair value has been introduced into the accounting measurement attributes, with the continuous introduction of financial innovation products and the widespread use of derivatives. Therefore, the problem of unrealized gains and losses arose. Initially, these items were presented directly as owner's equity section in the balance sheet, instead of the traditional performance statement. However, with the increase of unrealized gains and losses items, the traditional performance statement was increasingly unable to reflect enterprises business performance fully and objectively. The empirical study also shows that the decision usefulness of the performance statement decreased with time (Collins et al., 1997). For this reason, various accounting standards developing bodies and international organizations began to reform the traditional performance statement by presenting comprehensive income information. Comprehensive income (CI) is the change in equity in a period owing to transactions and other events, except those arising from investments by and distributions to owners. It is composed of two parts: traditional income (net income) and other comprehensive income (OCI).

In terms of the comprehensive income presentation, a large body of research focused on which statements present total CI, how to classify and where to present OCI and its components. CMF introduced the concepts of gains and losses by issuing "enterprise accounting standards" in 2006. Companies are required to present "the items of gains and losses directly recorded into the owner's equities" (i.e. OCI) in the equity statement. This presentation pattern is called "equity statement pattern". In 2009, CMF issued "enterprise accounting standards interpretation No. 3", which is the first official introduction of comprehensive income concept. It required companies to present "total CI" and "total OCI" in the performance statement as a supplement. Companies are required to disclose the components of $\mathrm{OCI}$ in the notes. The comprehensive income information is then present by extending the traditional performance statement in an appropriate way. This presentation pattern is called "performance statement transition pattern". In 2014, CMF issued the revised "accounting standards for enterprises No.30- presentation of financial statements"(CAS 30), which required companies to present all comprehensive income information in the performance statement, including classified information of OCI components. This presentation pattern is called "single performance statement pattern".

The empirical research shows that if the capital market is not sufficiently effective, the content and the accounting information report pattern are equally important to the user's decision-making (lmhoff et al.,1995). From 2006 to 2014, China has carried out two reforms on the comprehensive income reporting pattern. It provides a good opportunity to study the influence of different presentation patterns on the decision making of accounting information users. In this paper, we will investigate the impact of the presentation pattern changes on the value relevance of comprehensive income information (that is, the usefulness of decision making).

\subsection{Literature Review}

There is a large body of research devoted to the value relevance of comprehensive income information. The main research focuses on whether the CI has value relevance, whether $\mathrm{CI}$ is more associated with market value than traditional income (net income) (Biddle \& Choi, 2006; Dehning \& Ratliff, 2004; Devalle \& Magarini, 2012; Kanagaretnam et al., 2004). Whether total OCI and components of OCI have incremental value relevance is another research focus (Cahan et al., 2000; Lin, 2006; Mitra \& Hossain., 2009). however, very little previous research focuses on the influence of presentation pattern change on the value relevance of CI and OCI, based on the different presentation pattern.

Much previous research results indicate that presenting comprehensive income information in the performance statement can improve the information transparency. It helps the information users to make the right valuation decisions and increase the value relevance of comprehensive income. Hirst and Hopkins (1998) shows that the disclosure of comprehensive income information in the performance statement is more transparent than the disclosure in equity statement. It helps the analysts to make the correct value judgment. Maines and McDaniel (2000) shows that the presentation pattern affects how nonprofessional investors weight comprehensive income information. Investors' judgments on the corporate and management performance reflect the volatility of comprehensive income only when the comprehensive income is presented in the statement. Hunton et al. (2006) concludes that the disclosure of securities value changes in the income statement can enhance the transparency of this information. It reduces the intensive for managers to engage in earnings management. Xu and Zeng (2013) points out that presenting the change in the fair value of available-for-sale financial assets in the performance 
statement has more value-relevance than presenting it in equity statement. He (2014) argues that the disclosure of $\mathrm{OCI}$ in the notes has higher value relevance than the disclosure in equity statement. However, some research indicates different conclusions. Chambers et al. (2007) finds that OCI is more value relevant when reported in the equity statement than in the performance statement. Mechelli and Cimini (2014) suggests that the requirement of issuing a statement of comprehensive income has not produced a significant change in the value relevance of both CI and the total OCI of the period. Schaberl and Victoravich (2015) suggests that the value relevance of OCI is determined by whether its reporting location is consistent with the firm's reporting history. The value relevance of OCI decreased for firms that were required to change the reporting location of OCI from the equity statement to the performance statement.

In summary, the previous research has suggested that the presentation pattern affects the information decision-making, but the influence results have not yet reached the same conclusions. It is necessary to make further research on this issue. The purpose of this study is twofold: (1) to provide additional insights on whether the reporting location of $\mathrm{CI}$ and OCI matters to the value relevance; (2) to examine whether the single performance reporting is more value relevant than before.

\subsection{Research Hypothesis}

According to the traditional Efficient Markets Hypothesis(EMH), investors are able to completely understand the publicly disclosed information, no matter it is disclosed in the financial statements, in notes or in other parts of financial reports (Malkiel \& Fama, 1970). But previous experimental and empirical evidence is inconsistent with the EMH. The "Incomplete Revelation Hypothesis" (IRH) (Bloomfield, 2002) is the alternative theory. It argues that the irrationality of investors is ubiquitous, and the usefulness of accounting information is limited by the transparency of financial reports, the cost of obtaining information and the cognitive ability of investors. The higher the transparency of financial reports, the lower the cost of information acquisition, and then the stronger the cognitive ability of investors to improve the usefulness of accounting information value decision. By conducting a survey of securities analysts, Brown (1997) finds that the equity statement is the least valuable part of the financial report. It is not treated as a performance report. The experimental research by Hirst and Hopkins (1998), Maines and McDaniel (2000) shows that even reading the equity statement, the respondents do not treat OCI as the performance on the valuation basis. Ball (1992) and Hang (1990) argue that investors generally have a "lock up" habits. They tend to rely on the performance information for valuation, but pay less attention to equity information.

Based on the analysis above, at first presenting the comprehensive income information in equity statement, the information transparency in China is relatively low. Performance statement cannot reflect the future cash flow completely. Therefore, investors need search and process information beyond the performance statement in order to understand and predict future cash flow and company value. It increases the valuation costs. At the same time, there is no clear definition of comprehensive income in this stage. Investors are less aware of it. According to the analyses above, we make the first hypothesis:

Hypothesis 1: Under the equity statement pattern, CI and OCI did not have value relevance in 2007 and 2008.

In 2009, the "comprehensive income" is firstly defined in China which is conducive to improve the investors understanding. Meanwhile, unrealized and realized gains and losses were transferred to investors in a higher level of accounting statement (performance statement) in a concentrated and clear way. Financial reporting transparency is relatively high. At the same time, the costs and difficulty for valuation are reduced. It leads us to make the second hypothesis as follows:

Hypothesis 2: Under performance statement transition pattern, CI and OCI had value relevance from 2009 to 2013.

In 2014, China required firms to report the components of OCI in categories in the performance statement, instead of in the notes. It further increased the transparency and integrity of information disclosure. In addition, the classified report can reveal the nature of different benefits and further enhance the cognition of investors. It leads us to make the third hypothesis as follows:

Hypothesis 3: Under single performance statement pattern, CI and OCI had higher value relevance from 2014 to 2015 than that from 2009 to 2013.

\section{Samples, Data and Methodology}

\subsection{Samples and Data Sources}

In this paper, we use Shanghai Stock Exchange A shares listed companies from 2007 to 2015 as the primary 
sample. In line with previous studies, the companies with missing data, zero-OCI, financial firms; specially treated firms; non-standard audit opinion firms; extreme values of $1 \%$ samples at both ends of the sample are eliminated. 2972 valid observations were obtained. The specific distribution of sample firms in different presentation pattern is shown in Table 1:

Table 1. Sample firms distribution

\begin{tabular}{ccccc}
\hline year & $2007 \sim 2008$ & $2009 \sim 2013$ & $2014 \sim 2015$ & $2007 \sim 2015$ \\
\hline \multirow{2}{*}{ presentation pattern } & equity statement pattern & performance statement & single performance & Total \\
Number of Sample Firms & 388 & 1510 & statement pattern & 2972 \\
\hline
\end{tabular}

$\mathrm{CI}$ and OCI data are collected manually from annual reports issued by listed companies. The data for 2007 and 2008 are obtained from the equity statement. The data for 2009-2015 are obtained from the performance statement. Other data are collected mainly from the CSMAR database. The statistical software Eviews8.0 is used for the regression.

\subsection{Regression Models and Variable Description}

In this paper we use the price model (Ohlson,1995) as the basic research model. In order to test hypothesis 1 and hypothesis 2 we build the following regression model (1) and model (2):

Where:

$$
\begin{gathered}
P_{i t}=\beta_{0}+\beta_{1} * B V E_{i t}+\beta_{2} * C I_{i t}+\varepsilon_{i t} \\
P_{i t}=\beta_{0}+\beta_{1} * B V E_{i t}+\beta_{2} * N I_{i t}+\beta_{3} * O C I_{i t}+\varepsilon_{i t}
\end{gathered}
$$

$\mathrm{P}=$ the price per share 4 months after the end of fiscal year $\mathrm{t}$;

$\mathrm{BVE}=$ the book value of common equity per share at the end of the fiscal year $\mathrm{t}$;

$\mathrm{CI}=$ comprehensive income per share for the fiscal year $\mathrm{t}$;

$\mathrm{NI}=$ annual net income per share for the fiscal year $\mathrm{t}$;

$\mathrm{OCI}=$ other comprehensive income per share for the fiscal year $\mathrm{t}$;

$\beta_{2}$ in model (1) measures the value relevance of CI; $\beta_{3}$ in model (2) measures the value relevance of OCI.

To examine hypothesis 3 , we modify the model (1) and (2) and introduce interaction variables. CI_ Format is defined as CI*Format. OCI_ Format is defined as OCI*Format. Format is a dummy variable with the value 1 for firms which use a single performance statement to present comprehensive income information. That is to say, Format $=0$ for the period 2009 to 2013; Format $=1$ for the period 2014 to 2015. Model (3) and model (4) are as follows:

$$
\begin{gathered}
P_{i t}=\beta_{0}+\beta_{1} * B V E_{i t}+\beta_{2} * C I_{i t}+\beta_{3} * C I_{i t} \text { Format }_{+} \beta_{4} * \text { Format }+\varepsilon_{i t} \\
P_{i t}=\beta_{0}+\beta_{1} * B V E_{i t}+\beta_{2} * N I_{i t}+\beta_{3} * O C I_{i t}+\beta_{4} * O C I_{i t} \text { Format }+\beta_{5} * \text { Format }+\varepsilon_{i t}
\end{gathered}
$$

\section{Results and Analysis}

\begin{tabular}{|c|c|c|c|c|c|c|c|}
\hline year & Variable & Mean & Median & Maximum & Minimum & Std. Dev. & Observations \\
\hline \multirow{5}{*}{$2007-2008$} & $\mathrm{P}$ & 14.963 & 10.035 & 168.990 & 2.190 & 15.855 & \multirow{5}{*}{388} \\
\hline & NI & 0.372 & 0.257 & 5.893 & -1.492 & 0.544 & \\
\hline & BVE & 4.002 & 3.477 & 24.080 & 0.376 & 2.556 & \\
\hline & OCI & 0.133 & -0.001 & 20.128 & -7.546 & 1.675 & \\
\hline & $\mathrm{CI}$ & 0.505 & 0.252 & 20.326 & -7.462 & 1.773 & \\
\hline \multirow{5}{*}{$2009-2013$} & $\mathrm{P}$ & 11.069 & 8.400 & 108.920 & 1.670 & 9.172 & \multirow{5}{*}{1510} \\
\hline & NI & 0.373 & 0.272 & 2.730 & -3.810 & 0.469 & \\
\hline & BVE & 4.100 & 3.571 & 18.450 & -0.013 & 2.325 & \\
\hline & OCI & 0.020 & 0.005 & 7.959 & -4.015 & 0.420 & \\
\hline & $\mathrm{CI}$ & 0.393 & 0.302 & 8.702 & -4.237 & 0.671 & \\
\hline
\end{tabular}

\subsection{Descriptive Statistics}

From 2007 to 2015, the descriptive statistics for different presentation patterns are shown in Table 2:

Table 2. Descriptive statistics of variables (from 2007 to 2015) 


\begin{tabular}{|c|c|c|c|c|c|c|c|}
\hline \multirow{5}{*}{ 2014-2015 } & P & 16.435 & 12.815 & 218.190 & 2.890 & 14.146 & \multirow{5}{*}{1074} \\
\hline & NI & 0.384 & 0.278 & 13.440 & -3.688 & 0.749 & \\
\hline & BVE & 4.634 & 4.008 & 50.889 & -0.493 & 3.228 & \\
\hline & OCI & 0.050 & 0.023 & 7.389 & -2.740 & 0.422 & \\
\hline & CI & 0.434 & 0.320 & 14.246 & -5.515 & 0.939 & \\
\hline
\end{tabular}

Table 2 indicates that the majority of our observations are profitable over the period 2007-2015. The mean results suggest that, compared with net income per share, the proportion of OCI per share in total CI per share is not high. Traditional earnings are still the main source of performance for listed companies.

\subsection{Regression Results and Analysis}

From 2007 to 2008, the regression results of the comprehensive income information under equity statement pattern are shown in Table 3:

Table 3. The regression results under equity statement pattern(2007-2008)

\begin{tabular}{|c|c|c|c|c|c|}
\hline \multicolumn{3}{|c|}{ Model (1) } & \multicolumn{3}{|c|}{ Model (2) } \\
\hline Coefficient & Value & P-value & Coefficient & Value & P-value \\
\hline$\beta 0$ & $4.410 * * *$ & 0.003 & $\beta 0$ & $5.034 * * *$ & 0.000 \\
\hline$\beta 1$ & $2.546^{* * * *}$ & 0.000 & $\beta 1$ & $1.138 * * *$ & 0.002 \\
\hline \multirow[t]{2}{*}{$\beta 2$} & 0.718 & 0.176 & $\beta 2$ & $14.217 * * *$ & 0.000 \\
\hline & & - & $\beta 3$ & 0.671 & 0.156 \\
\hline \multicolumn{2}{|c|}{ Adjusted $\mathrm{R}^{2}$} & 0.218 & Adjusted $\mathrm{R}^{2}$ & \multicolumn{2}{|c|}{0.376} \\
\hline \multicolumn{2}{|c|}{ Observations } & 388 & Observations & \multicolumn{2}{|c|}{388} \\
\hline
\end{tabular}

Note. ${ }^{* *}, * *, *$ indicates $\mathrm{p}<0.01, \mathrm{p}<0.05$, and $\mathrm{p}<0.10$. The same below.

Table 3 results show that from 2007 to 2008, both the coefficients of CI and OCI are statistically insignificant. That is to say, neither of them has the value relevance. Hypothesis 1 cannot be rejected. The results of the comprehensive income information in the period from 2009 to 2013, under the performance statement transition pattern, are shown in Table 4:

Table 4. The regression results under performance statement transition pattern(2009-2013)

\begin{tabular}{cccccc}
\hline & Model (1) & & \multicolumn{2}{c}{ Model (2) } \\
\hline Coefficnent & Value & P-value & Coefficient & Value & P-value \\
\hline$\beta 0$ & $8.711^{* * *}$ & 0.000 & $\beta 0$ & $7.209 * * *$ & 0.000 \\
$\beta 1$ & 0.012 & 0.163 & $\beta 1$ & 0.006 & 0.448 \\
$\beta 2$ & $5.511^{* * *}$ & 0.000 & $\beta 2$ & $10.249 * * *$ & 0.000 \\
& & & $\beta 3$ & $0.762^{*}$ & 0.100 \\
\hline Adjusted $\mathrm{R}^{2}$ & & 0.165 & Adjusted $\mathrm{R}^{2}$ & & 0.277 \\
Observations & 1510 & \multicolumn{3}{c}{ Observations } \\
\hline
\end{tabular}

Table 4 results show that from 2009 to 2013, the coefficients of CI and OCI are both positive, and statistically significant at both $1 \%$ and $10 \%$ level, under the performance statement transition pattern. That is to say, both CI and OCI have the value relevance. Hypothesis 2 cannot be rejected.

The regression results of the comprehensive income information in the period from 2014 to 2015, under the single performance statement pattern, are shown in Table 5:

Table 5. The regression results under single performance statement pattern(2014-2015)

\begin{tabular}{|c|c|c|c|c|c|}
\hline \multicolumn{3}{|c|}{ Model (3) } & \multicolumn{3}{|c|}{ Model (4) } \\
\hline Coefficient & Value & $\mathrm{P}$-value & Coefficient & Value & $\mathrm{P}$-value \\
\hline$\beta 0$ & $3.821 * * *$ & 0.000 & $\beta 0$ & $4.278 * * *$ & 0.000 \\
\hline$\beta 1$ & $1.498 * * *$ & 0.000 & $\beta 1$ & $0.865 * * *$ & 0.000 \\
\hline$\beta 2$ & $2.628 * * *$ & 0.000 & $\beta 2$ & $8.681 * * *$ & 0.000 \\
\hline$\beta 3$ & $1.800 * * *$ & 0.000 & $\beta 3$ & 0.179 & 0.748 \\
\hline \multirow[t]{2}{*}{$\beta 4$} & $3.597 * * *$ & 0.000 & $\beta 4$ & -0.904 & 0.293 \\
\hline & & & $\beta 5$ & $4.852 * * *$ & 0.000 \\
\hline Adjusted $\mathrm{R}^{2}$ & \multicolumn{2}{|c|}{0.354} & Adjusted $\mathrm{R}^{2}$ & \multicolumn{2}{|c|}{0.412} \\
\hline Observations & \multicolumn{2}{|c|}{1074} & Observations & \multicolumn{2}{|c|}{1074} \\
\hline
\end{tabular}


Table 5 results show that, compared with the period 2009-2013, the coefficient of CI_format is statistically significantly positive at the level of $1 \%$ during the period 2014-2015, under single performance statement pattern. That is to say, the value relevance of $\mathrm{CI}$ is significantly improved. The coefficient of OCI_format is not significant. In other words, the value relevance of OCI does not increase significantly. Hypothesis 3 cannot be rejected partially.

\section{Conclusion}

This paper examines the impact of presentation pattern change on the value relevance of comprehensive income information, based on the background of the two reforms of comprehensive income presentation pattern from 2006 to 2014 in China. The results suggest that, (1) from 2007 to 2008, CI and OCI have no value relevance under the equity statement pattern; (2) from 2009 to 2013, CI and OCI have value relevance under performance statement transition pattern; (3) compared with the period 2009-2013, the value relevance of CI is improved during the period 2014-2015 under the single performance statement pattern. However, the value relevance of OCI does not increase significantly in the same period.

The results imply that, the usefulness of accounting information will be affected by the transparency and clarity of financial reporting, the cost of obtaining information and the cognitive ability of investors. Performance statement pattern can improve the quality of information reporting. After 2014, entities are required to present components of OCI in categories. The items that will be never recognized in profit or loss should be presented separately from those that are subject to subsequent reclassification(recycling). Although the classified report can reveal the nature of different income, the current accounting standards have not yet solved the problem of accounting recognition of OCI. In addition, there is no clear standard to distinguish which items can be reclassified, which cannot. These factors may increase the difficulty for accounting information users to understand OCI presentation contents. As a result, information users may not fully use OCI information to make value judgment. It is necessary to further strengthen the theoretical research and implementation instructions about OCI classification report in the future.

\section{Acknowledgments}

This paper is one part of the research project "A study on the value relevance of comprehensive income: from the perspective of the report model (project number: KYJJ2012-08-10)," which is supported by Science Foundation for the Excellent Youth Scholars in China University of Petroleum, Beijing. As well as the research project "the reform of delisting system, the persistence of earnings and the pricing behavior of the market (project number: 2462015YQ0702)" Supported by Science Foundation for the Excellent Youth Scholars in China University of Petroleum, Beijing. This work is supported by Beijing Natural Science Foundation (9164034).

\section{References}

Ball, R. (1992). The earnings-price anomaly. Journal of Accounting and Economics, 15(2), 319-345. https://doi.org/10.1016/0165-4101(92)90023-U

Biddle, G. C., \& Choi, J. H. (2006). Is comprehensive income useful? Journal of Contemporary Accounting and Economics, 2(1), 1-32. http://doi.org/10.1016/S1815-5669(10)70015-1

Bloomfield, R. J. (2002). The "incomplete revelation hypothesis" and financial reporting. Accounting Horizons, 16(3), 985-988. http://dx.doi.org/10.2308/acch.2002.16.3.233

Brown, P. R. (1997). Financial data and decision making by sell-side analysts. Journal of Financial Statement Analysis, (spring), 43-48

Cahan, S. F., Courtenay, S. M., Gronewoller, P. L., \& Upton, D. R. (2000). Value relevance of mandated comprehensive income disclosures. Journal of Business, Finance and Accounting, 27(9), 1273-1301. http://dx.doi.org/10.1111/1468-5957.00356

Chambers, D. J., Linsmeier, T. J., Shakespeare, C., \& Sougiannis, T. (2007). An evaluation of SFAS No. 130 comprehensive income disclosures. Review of Accounting Studies, 12(4), 557-593. http://dx.doi.org/10.1007/s11142-007-9043-2

Collins, D. W., Maydew, E. L., \& Weiss, I. S. (1997). Changes in the value-relevance of earnings and book values over the past forty years. Journal of Accounting \& Economics, 24(1), 39-67. https://doi.org/10.1016/S0165-4101(97)00015-3

Dehning, B., \& Ratliff, P. A. (2004). Comprehensive Income: Evidence on the Effectiveness of FAS 130. The Journal of American Academy of Business, (March), 228-232. Retrieved from http://www.sahandtarjomeh.com/wp-content/uploads/2013/12/sasfdf2+++.pdf 
Devalle, A., \& Riccardo, M. (2012). Assessing the value relevance of total comprehensive income under IFRS: An empirical evidence from European stock exchanges. International Journal of Accounting, Auditing and Performance Evaluation, 8(1), 43. http://dx.doi.org/10.1504/IJAAPE.2012.043965

Hang, J. (1990). A test of the extended functional fixation hypothesis. The Accounting Review, 65(3), 740-763. Retrieved from http://www.jstor.org/stable/247648

He, H. (2014). Information disclosure system and the value relevance of other comprehensive income. Financial Research, (1), 73-76.

Hirst, D., \& Hopkins, P. (1998). Comprehensive income reporting and analysts' valuation judgments. Journal of Accounting Research, 36, 47-74. http://dx.doi.org/10.2307/2491306

Hunton, J., Libby, R., \& Mazza, C. (2006). Financial reporting transparency and earnings management. The Accounting Review, 81(1), 135-157. http://dx.doi.org/10.2308/accr.2006.81.1.135

Kanagaretnam, K., Mathieu, R., \& Shehata, M. (2004) .Usefulness of comprehensive income reporting in Canada. Journal of Accounting and Public Policy, 28(4), 349-365. http://doi.org/10.1016/j.jaccpubpol.2009.06.004

Lin, S. W. (2006). Testing the information set perspective of UK financial report standard no. 3: Reporting financial performance. Journal of Business Finance and Accounting, 33(7-8), 1110-1141. http://dx.doi.org/10.1111/j.1468-5957.2006.00595.x

Lmhoff,E.A.,Lipe,R.C.,\&Wright,D.(1995). Is footnote disclosure an adequate alternative to financial statement recognition. Journal of financial statement analysis, (fall):55-59.

Maines, L., \& McDaniel, L. (2000). Effects of comprehensive-income characteristics nonprofessional investors' judgments: The role of financial statement presentation format. The Accounting Review, 75(2), 179-207. http://dx.doi.org/10.2308/accr.2000.75.2.179

Malkiel, B. G., \& Fama, E. F. (1970). Efficient capital markets: A review of theory and empirical work. The Journal of Finance, 25(2), 383-417. http://dx.doi.org/10.2307/2325486

Mechelli, A., \& Cimini, R. (2014). Is comprehensive income value relevant and does location matter? A European study. Accounting in Europe, 11(1), 59-87. http://dx.doi.org/10.1080/17449480.2014.890777

Mitra, S., \& Hossain, M. (2009) .Value-relevance of pension transition adjustments and other comprehensive income components in the adoption year of SFAS No. 158. Review of Quantitative Finance and Accounting, 33(3), 279-301. http://dx.doi.org/10.1007/s11156-009-0112-4

Ohlson, J. (1995). Earnings, book Values, and dividends in equity valuation. Contemporary Accounting Research, 11(2), 661-687. http://dx.doi.org/10.1111/j.1911-3846.1995.tb00461.x

Schaberl, P. D., \& Victoravich, L. M. (2015). Reporting location and the value relevance of accounting information: The case of other comprehensive income. Advances in Accounting, 31(2), 239-246. http://dx.doi.org/10.1016/j.adiac.2015.09.006

Xu, J. C., \& Zeng, X. Y. (2013). The Presentation Format of Comprehensive Income and the Value-Relevance of Fair Value. Accounting Research, (1), 20-27.

\section{Copyrights}

Copyright for this article is retained by the author(s), with first publication rights granted to the journal.

This is an open-access article distributed under the terms and conditions of the Creative Commons Attribution license (http://creativecommons.org/licenses/by/4.0/). 